\title{
Microwaves and Alzheimer's disease (Review)
}

\author{
XIA ZHANG, WEN-JUAN HUANG and WEI-WEI CHEN \\ Department of Neurology, Xuzhou Central Hospital, Xuzhou, Jiangsu 221009, P.R. China
}

Received February 3, 2016; Accepted July 25, 2016

DOI: $10.3892 /$ etm.2016.3567

\begin{abstract}
Alzheimer's diseases (AD) is the most common type of dementia and a neurodegenerative disease that occurs when the nerve cells in the brain die. The cause and treatment of $\mathrm{AD}$ remain unknown. However, $\mathrm{AD}$ is a disease that affects the brain, an organ that controls behavior. Accordingly, anything that can interact with the brain may affect this organ positively or negatively, thereby protecting or encouraging AD. In this regard, modern life encompasses microwaves for all issues including industrial, communications, medical and domestic tenders, and among all applications, the cell phone wave, which directly exposes the brain, continues to be the most used. Evidence suggests that microwaves may produce various biological effects on the central nervous system (CNS) and many arguments relay the possibility that microwaves may be involved in the pathophysiology of CNS disease, including AD. By contrast, previous studies have reported some beneficial cognitive effects and that microwaves may protect against cognitive impairment in AD. However, although many of the beneficial effects of microwaves are derived from animal models, but can easily be extrapolated to humans, whether microwaves cause AD is an important issue that is to be addressed in the current review.
\end{abstract}

\section{Contents}

1. Introduction

2. Possibility of microwaves causing AD

3. Conclusion

\section{Introduction}

Microwaves can be arbitrary and basically defined as extremely high frequency radiowaves created by several types of transmitters, including chip and antenna for mobile phone

Correspondence to: Dr Wen-Juan Huang, Department of Neurology, Xuzhou Central Hospital, 199 Jiefang South Road, Xuzhou, Jiangsu 221009, P.R. China

E-mail: nmsdp2137@163.com

Key words: Alzheimer's disease, central nervous system or 'magnetron' for kitchen microwaves (1). With wavelengths of merely a couple of centimeters, microwave ovens cause fat molecules and water vibration, making these substances hot and allowing the capacity to cook many types of food (2). Microwaves used by fixed traffic speed cameras or radar for aircraft ships and weather for casters commonly emit bursts of microwaves, detecting echoes coming back from the objects they strike, and using the time it takes for the echoes to return to determine the distance to a particular object or location $(1,2)$. Contact with certain types of microwaves, together with cordless phones, Wi-Fi, walkie-talkies, ham radio transmitters and other devices are not considered harmful exposure, whereas these types of microwaves constitute the same risk as using a cell phone. Indeed, the body tissue, mostly in the lower body has good conductivity and absorbance of radiation. For example, men wearing cell phones near their groin could reduce their sperm count by $30 \%$ (3). Accordingly, cell phone radiation decreases as the distance from the cell phone increases, resulting in marked effects, even if the cell phone is only a short distance away. By contrast, the use of headsets connected to the cell phone may greatly reduce the absorbed cell phone radiation (4), while wearing an air-tube headset has been found to intensify radiation into the ear canal (5), the wire being a transmitter of radiation and serving as an antenna that can attract electromagnetic fields (EMFs) from the surroundings (6). Microwaves used by mobile cells are generated by a small antenna and are transmitted by a line of sight to the transmitter. The prolonged exposure to microwaves has been associated with negative effects on the eyes (7) and recent findings indicated that holding the transmitter of a cell phone close to the head induces detrimental effects on the brain $(8,9)$.

Investigations have suggested that using a cell phone for 10 years or more may significantly increase the risk of developing a tumor (10) thereby doubling the risk of developing glioma or acoustic neuroma in the more exposed brain hemisphere (11). Long-term cell phone use is associated with the likelihood of being hospitalized for migraines and vertigo by $10-20 \%$ (8) since the mobile phone signal is absorbed deeply into the brain, up to 2 inches into the adult skull (12). In children, their developing skulls offers a higher opportunity for radiation to penetrate more deeply (13), and thus it is crucial to emphasize the vulnerability of youth brains to microwaves (14). It has been previously shown that adult brain almost entirely absorbs radiations on the ipsilateral part where the phone is held, but not on the contralateral part. Consequently, the ipsilateral temporal lobe or cerebellum absorbed $50-60$ or $12-25 \%$, respectively, of the total radiation, while the insular region 
and overlying skull, scalp and parotid gland tissues are also exposed (15). Additionally, the exposition seems to be even higher in children owing to thinner scalps and skulls, increased water content of their brain and lower brain volume (16). The results of studies on radiofrequency EMFs examining the effects of mobile phone-related exposures at the level of the head on physiological functions such as brain electrical activity (EEG), cognition, brain vascularization, cardiovascular and endocrine systems were not conclusive. The main observation was the effects on the amplitude of EEG $\alpha$ wave during sleep while there was no consensus on the cognitive effects. However, the definite association of EEG $\alpha$ wave with cerebrovascular effects requires further investigation (17). In rat, exposition to low-power-density microwave fields resulted in increased levels of plasma corticosterone and glucocorticoid receptor nuclear translocation, as well as apoptosis in the hippocampus affecting spatial learning and memory (18), following exposure to a dose of microwaves comparable to those received by human in normal utilization (10).

In agreement with these data, investigations have been conducted into mobile phone handsets and findings indicate that some phones can cause higher rates of brain tumors (19) including new mobile phones, which by contrast to outdated analogue phones, emit much stronger signals that may be damaging to the health. However, despite these data, the overall scientific opinion states that the benefits of mobile phones seem to outweigh any danger, albeit the utilization of cell phones must respect a precautionary approach, according to conclusions of the Stewart Report published in 2000 (20). Nevertheless, data arguing in favor of the possibility that phone microwave range may be harmful to the human health (21), whether the long-term effects of a cell phone can induce the development of Alzheimer's disease (AD), the state of dementia and neurodegenerative disease that occurs when the nerve cells in the brain die remains to be determined $(22,23)$. In this review, we examine whether microwaves cause AD.

\section{Possibility of microwaves causing AD}

The introduction of cell phones, Wi-Fi, satellite and wireless communications and the microwave oven have had a significant impact on daily life. However, there are growing concerns regarding the potential health risks associated with increased, frequency, modulation frequency and duration of microwave exposure $(24,25)$ and particularly, the risk of developing $A D$, an incurable and debilitating disease affecting individuals worldwide being associated with the death of nerve cells in the brain, cerebrovascular impairments and dementia $(22,23)$.

An increase of major symptoms has become evident for individuals residing at a distance of $<500 \mathrm{~m}$ from a mobile phone base station, including irritability, headache, and lower cognitive performance (26). Of note, an increase of intracellular $\mathrm{Ca}^{2+}$ levels that coincided with the overactivation of the GABA receptor NMDA, which activates CaMKII, has been observed in cell cultures exposed to microwaves. NMDA is important in the regulation of induction of synaptic plasticity modifications such as long-term potentiation (LTP) (27), a physiological mechanism of learning memory formation that was actually inhibited by microwave (25), suggesting that exposure to microwaves can result in alterations of synaptic structure, amino acid neurotransmitter release, calcium influx and NMDA receptor signaling molecules (microwave exposure impairs synaptic plasticity in the rat hippocampus and PC12 cells through overactivation of the NMDA receptor signaling pathway) (28). Accordingly, experimental studies have revealed that long-term microwave exposure, even low levels of radiation power $(29,30)$, were associated with a significant decrease in learning and memory activity reminiscent of neuronal degeneration and enlargement perivascular spaces in the hippocampus that produce adverse biological effects in the nervous system, while the effects on cognitive functions remained controversial (31-33). Notably, the low-level and long-term microwave exposure of rats have led to marked alteration in the structure and function of the hippocampus, including mitochondrial swelling, cristae disorders $(34,35)$ as well as an increase in the concentration of neurotransmitters glutamate (Glu), aspartic acid (Asp), glycine (Gly) and $\gamma$ aminobutyric acid (GABA) (34). The rough endoplasmic reticulum also exhibited sacculated distension and there was a decrease in the quantity of synaptic vesicles, suggesting detrimental effects of microwaves on synaptic plasticity and cognitive function, especially in learning and memory $(36,37)$. In line with these data, Glu, Gly, Asp and GABA are neurotransmitters playing critical roles in processes such as learning and memory activities $(38,39)$, sleep-wake cycle $(40)$ response $(41)$, induction of pain (42) reaction time in behavioral and brain plasticity (43) as well as in various central nervous system (CNS) diseases (44). Taken together, these data indicate serious hazards related to the overuse of the cell phone, and thus mostly provide detrimental potential effects of microwaves on the brain that may lead to the development of AD. Nevertheless, some reports in animal models suggest stimulatory or beneficial effects following exposure to cell phone radiofrequency radiation (45). For example, beneficial cognitive effects, including a decrease in reaction time after human short-term exposure to cell phone radiation or occupational exposure to radar microwave after short-term exposure to radar microwave radiation have been documented in rats $(46,47)$. Such studies found that exposure may exhibit an increase in brain glucose consumption and suggested that radiofrequency radiation may protect against cognitive impairment in $\mathrm{AD}(45,46,48,49)$.

\section{Conclusion}

The impact of wireless communication on human health is a mater of debate. Since there are widespread concerns regarding the deleterious effects of the exposure to microwaves on human tissues and the subsequent potential threat of carcinogenesis, we can conclude that the current exposure to microwaves during the use of cell phones is not safe for long-term exposure, despite the current scientific opinion. Absorption of the cell phone signal into the brain of children does not exclude serious neuronal damage, as evidenced in rat studies (50). In addition, the increased risk of tumors of the head associated with long-term cell phone use is evident since radiofrequency may cause the blood-brain barrier to leak and to favor the damage of genetic material which consists of common precursors to cancer (51). Accordingly, poor fertility and the increased chance of miscarriage and childhood cancer have been associated with cell phone storage in front 
pockets. Notably, the data suggested that the hippocampus can be injured by long-term microwave exposure (52), which may result in the impairment of cognitive function due to neurotransmitter disruption. These results suggest that precautionary approach underlying the restrictive use of cell phones constitutes essential appropriate guidelines to follow although additional studies are needed.

\section{References}

1. Georgiadis A, Rogier H, Roselli L and Arcioni P: Microwave and Millimeter Wave Circuits and Systems: Emerging Design, Technologies, and Applications. John Wiley \& Sons, 2012.

2. Kalafat SR, Kroger M and Decareau RV: Microwave heating of foods - use and safety considerations. Crit Rev Food Sci Nutr 4: 141-151, 1973.

3. Hope J: Men who use mobile phones face increased risk of infertility. http://www.dailymail.co.uk/news/article-412179/Men-use-mobilephones-face-increased-risk-infertility.html.

4. Wood AW, Loughran SP and Stough C: Does evening exposure to mobile phone radiation affect subsequent melatonin production? Int J Radiat Biol 82: 69-76, 2006.

5. Puthuff SH, Pluvinage V and Taenzer JC: Wired open ear canal earpiece. US Patent 6181801 B1. Filed April 3, 1987; issued January 30, 2001.

6. Stutzman WL and Thiele GA: Antenna Theory and Design. 3rd edition. John Wiley \& Sons, Hoboken, NJ, 2012.

7. Prausnitz S and Sütsskind C: Effects of chronic microwave irradiation on mice. Ire Trans Biomed Electron 9: 104-108, 1962.

8. Dubey RB, Hanmandlu M and Gupta SK: Risk of brain tumors from wireless phone use. J Comput Assist Tomogr 34: 799-807, 2010.

9. Behari J: Biological responses of mobile phone frequency exposure. Indian J Exp Biol 48: 959-981, 2010.

10. Inskip PD, Tarone RE, Hatch EE, Wilcosky TC, Shapiro WR, Selker RG, Fine HA, Black PM, Loeffler JS and Linet MS: Cellular-telephone use and brain tumors. N Engl J Med 344: 79-86, 2001.

11. Hardell L, Carlberg M and Mild KH: Use of mobile phones and cordless phones is associated with increased risk for glioma and acoustic neuroma. Pathophysiology 20: 85-110, 2013.

12. Klatz R and Goldman R: Cellular Phones: Medical Menaces of a Modern-Day Convenience. 3rd edition. The American Academy of Anti-Aging Medicine, Chicago, IL, 2009.

13. DeLaney TF, Trofimov AV, Engelsman M and Suit HD: Advanced-technology radiation therapy in the management of bone and soft tissue sarcomas. Cancer Contr 12: 27-35, 2005.

14. Vienneau D, Infanger D, Feychting M, Schüz J, Schmidt LS, Poulsen AH, Tettamanti G, Klæboe L, Kuehni CE, Tynes T, et al: A multinational case-control study on childhood brain tumours, anthropogenic factors, birth characteristics and prenatal exposures: a validation of interview data. Cancer Epidemiol 40: $52-59,2016$.

15. Thies R: Neurophysiology. In: Physiology. 4th edition. Springer, New York, NY, pp29-74, 1995.

16. Khurana VG, Teo C, Kundi M, Hardell L and Carlberg M: Cell phones and brain tumors: a review including the long-term epidemiologic data. Surg Neurol 72: 205-214, 2009.

17. Ghosn R, Villegier AS, Selmaoui B, Thuróczy G and De Seze R: Effets des radiofréquences sur le système nerveux central chez l'homme: EEG, sommeil, cognition, vascularisation. C R Phys 14: 395-401, 2013 (In French).

18. Li M, Wang Y, Zhang Y, Zhou Z and Yu Z: Elevation of plasma corticosterone levels and hippocampal glucocorticoid receptor translocation in rats: a potential mechanism for cognition impairment following chronic low-power-density microwave exposure. J Radiat Res (Tokyo) 49: 163-170, 2008.

19. Moulder J, Foster K, Erdreich L and McNamee J: Mobile phones, mobile phone base stations and cancer: a review. Int J Radiat Biol 81: 189-203, 2005.

20. Rothman KJ: Epidemiological evidence on health risks of cellular telephones. Lancet 356: 1837-1840, 2000.

21. Breckenkamp J, Berg G and Blettner M: Biological effects on human health due to radiofrequency/microwave exposure: a synopsis of cohort studies. Radiat Environ Biophys 42: 141-154, 2003 .
22. Morrison JH and Hof PR: Life and death of neurons in the aging brain. Science 278: 412-419, 1997.

23. Law C, Schaan Profes M, Levesque M, Kaltschmidt JA, Verhage $\mathrm{M}$ and Kania A: Normal molecular specification and neurodegenerative disease-like death of spinal neurons lacking the SNARE-associated synaptic protein Munc18-1. J Neurosci 36: 561-576, 2016.

24. Corle C, Makale M and Kesari S: Cell phones and glioma risk: a review of the evidence. J Neurooncol 106: 1-13, 2012.

25. Wang H, Peng R, Zhou H, Wang S, Gao Y, Wang L, Yong Z, Zuo H, Zhao L, Dong J, et al: Impairment of long-term potentiation induction is essential for the disruption of spatial memory after microwave exposure. Int J Radiat Biol 89: 11001107,2013

26. Khurana VG, Hardell L, Everaert J, Bortkiewicz A, Carlberg M and Ahonen M: Epidemiological evidence for a health risk from mobile phone base stations. Int J Occup Environ Health 16 263-267, 2010

27. Liu XB and Murray KD: Neuronal excitability and calcium/calmodulin-dependent protein kinase type II: location, location, location Epilepsia 53: 45-52, 2012.

28. Xiong ZH, Wang L, Zhou JG and Liu JM: Thermodynamics and kinetics of adsorption of diclofenac on magnetic multiwalled carbon nanotubes in an aqueous solution. Wuli Huaxue Xuebao 26: 2890-2898, 2010.

29. Xu S, Ning W, Xu Z, Zhou S, Chiang H and Luo J: Chronic exposure to GSM $1800-\mathrm{MHz}$ microwaves reduces excitatory synaptic activity in cultured hippocampal neurons. Neurosci Lett 398: 253-257, 2006

30. Zhao L, Peng RY, Wang SM, Wang LF, Gao YB, Dong J, Li X and Su ZT: Relationship between cognition function and hippocampus structure after long-term microwave exposure. Biomed Environ Sci 25: 182-188, 2012.

31. Leszczynski D and Xu Z: Mobile phone radiation health risk controversy: the reliability and sufficiency of science behind the safety standards. Health Res Policy Syst 8: 2, 2010.

32. Wiedemann P and Schütz H: Children's health and RF EMF exposure. Views from a risk assessment and risk communication perspective. Wien Med Wochenschr 161: 226-232, 2011.

33. Jorge-Mora T, Alvarez Folgueiras M, Leiro-Vidal JM, Jorge-Barreiro F, Ares-Pena FJ and López-Martin E: Exposure to $2.45 \mathrm{GHz}$ microwave radiation provokes cerebral changes in induction of Hsp-90 $\alpha / \beta$ heat shock protein in rat. Prog Electromagnetics Res 100: 351-379, 2010.

34. Zhao L, Peng RY, Wang SM, Wang LF, Gao YB, Dong J, Li X and Su ZT: Relationship between cognition function and hippocampus structure after long-term microwave exposure. Biomed Environ Sci 25: 182-188, 2012.

35. Somoy Z: Radiation response of cell organelles. Micron 31: $165-181,2000$

36. Naraynan SN, Kumar RS, Potu BK, Nayak S and Mailankot M: Spatial memory performance of Wistar rats exposed to mobile phone. Clinics (Sao Paolo) 64: 231-234, 2009.

37. Ning W, Xu SJ, Chiang H, Xu ZP, Zhou SY, Yang W and Luo JH: Effects of GSM $1800 \mathrm{MHz}$ on dendritic development of cultured hippocampal neurons. Acta Pharmacol Sin 28: 1873-1880, 2007.

38. Nittby H, Grafström G, Tian DP, Malmgren L, Brun A, Persson BR, Salford LG and Eberhardt J: Cognitive impairment in rats after long-term exposure to GSM-900 mobile phone radiation. Bioelectromagnetics 29: 219-232, 2008.

39. Paulraj R and Behari J: Enzymatic alterations in developing rat brain cells exposed to a low-intensity $16.5 \mathrm{GHz}$ microwave radiation. Electromagn Biol Med 31: 233-242, 2012

40. Lu Y, Xu S, He M, Chen C, Zhang L, Liu C, Chu F, Yu Z, Zhou Z and Zhong M: Glucose administration attenuates spatial memory deficits induced by chronic low-power-density microwave exposure. Physiol Behav 106: 631-637, 2012.

41. Gerrow K and Triller A: Synaptic stability and plasticity in a floating world. Curr Opin Neurobiol 20: 631-639, 2010.

42. Kruges HJ, Zhou M, Joëls M and Kindt M: Regulation of excitatory synapses and fearful memories by stress hormones. Front Behav Neurosci 5: 62, 2011.

43. Wang L, Peng R, Hu X, Gao Y, Wang S, Zhao L, Dong J, Su Z, $\mathrm{Xu} \mathrm{X}$, Gao R, et al: Abnormality of synaptic vesicular associated proteins in cerebral cortex and hippocampus after microwave exposure. Synapse 63: 1010-1016, 2009.

44. Monahan DT, Bridges RJ and Cotman CW: The excitatory amino acid receptors: their classes, pharmacology, and distinct properties in the function of the central nervous system. Annu Rev Pharmacol Toxicol 29: 365-402, 1989. 
45. Mortazavi S, Mosleh-Shirazi M, Tavassoli A, Taheri M, Mehdizadeh A, Namazi S, Jamali A, Ghalandari R, Bonyadi S, Haghani M, et al: Increased radioresistance to lethal doses of gamma rays in mice and rats after exposure to microwave radiation emitted by a GSM mobile phone simulator. Dose Response 11: 281-292, 2012.

46. Mortazavi SM, Rouintan MS, Taeb S, Dehghan N, Ghaffarpanah AA, Sadeghi Z and Ghafouri F: Human short-term exposure to electromagnetic fields emitted by mobile phones decreases computer-assisted visual reaction time. Acta Neurol Belg 112: 171-175, 2012.

47. Mortazavi SMJ, Shahram T and Dehghan N: Alterations of visual reaction time and short term memory in military radar personnel. Iran J Public Health 42: 428, 2013.
48. Preece AW, Iwi G, Davies-Smith A, Wesnes K, Butler S, Lim E and Varey A: Effect of a 915-MHz simulated mobile phone signal on cognitive function in man. Int J Radiat Biol 75: 447-456, 1999

49. Mortazavi SMJ and Mozdarani H: Non-linear phenomena in biological findings of the residents of high background radiation areas of Ramsar. Int J Radiat Res 11: 3-9, 2013.

50. Maisch D: Children and cell phones: is there a health risk? The case for extra precautions. J Australas Coll Nutr Environ Med 22: 3-8, 2003.

51. Yuzhaln A and Kutikhin A: Interleukins in Cancer Biology: Their Heterogeneous Role. 1st edition. Academic Press, 2014.

52. New P: Radiation injury to the nervous system. Curr Opin Neurol 14: 725-734, 2001. 